\title{
Activation of phonological codes during reading: Evidence from eye movements
}

\author{
Laurent Sparrow and Sébastien Miellet
}

UPRES URECA, Université de Lille 3, Villeneuve d'Ascq Cedex, France

\begin{abstract}
This experiment explored the role of phonology in the activation of word meanings when homophonic and non homophonic errors were embedded in meaningful texts. The resulting data supported the position that phonological codes are activated very early in an eye fixation and are compatible with the verification model of Van Orden (1987).
\end{abstract}

Key Words: phonological activation ; eye movements ; reading ; verification model ; phonological mediation.

\section{INTRODUCTION}

This experiment explored the role of phonology in the activation of word meanings. Much of the evidence for the involvement of phonology in lexical access comes from tasks showing homophone confusion effects. One such task is lexical decision in which subjects judge whether a given letter string is a word. A typical finding is that participants take more time to reject pseudohomophones foils than controls foils (Rubenstein, Lewis, \& Rubenstein, 1971). Another task showing homophone confusions to single words is the categorization task in which subjects decide whether a target word is a member of a given category (Van Orden, 1987; Van Orden, Johnston \& Hale, 1988). The typical finding is that participants make more false categorization responses to homophones, which sounds like the genuine category member, than they do to controls, which are orthographically similar to category exemplars but does not sound like it. Homophone confusions have also been demonstrated in tasks that require readers to make semantic decisions about an entire sentence (V.Coltheart, Avons \& Trollope, 1990) and in proofreading study (Daneman \& Stainton, 1991). The finding that homophonic words are misinterpreted as their sound-alike mates has been taken as evidence for phonology playing an early and dominant role in accessing word meanings.

In addition, a number of recent eye movement studies are consistent with the idea that phonological codes are used early in identifying a word during reading. Inhoff \& Topolski (1994) examined fixation times when subjects read short texts that contained pseudohomophones or pseudowords spelling controls. In this study, participants read each text and then decided whether it made sense, as in sentence verification experiments. Inhoff and Topolski found that first fixation durations and gaze durations were significantly shorter for pseudohomophones than for spelling controls, which suggests that phonological representation of the pseudohomophones activated the meaning corresponding to the correct target word. Consistent with this interpretation, participants falsely accepted more of the pseudohomophones error sentences than pseudowords error sentences.

Rayner, Pollatsek \& Binder (1998) also provided evidence that phonology plays an important role in reading for meaning. In their study, subjects read short passages of text that contained a single target homophone (or its homophone mate or a spelling control). Target homophones were either predictable or not predictable from the context. When homophones were predictable, first-fixation durations on homophone errors did not differ from those for correct target words and were 
significantly shorter than for spelling controls. In contrast, gaze duration were significantly longer on homophone errors than on correct target words. However, gaze duration on homophone errors were shorter than for spelling controls. When homophones were not predictable from the context, homophones errors had significantly longer fixations than correct target words and significantly shorter fixations than spelling controls in first-fixation and gaze-duration (experiment 3). Rayner et al. (1998) appeal to the verification model of lexical access (Van Orden, 1987) to explain their results. In this model, the phonological representation is activated immediately and used to gain access to a word's semantic representation, with the orthographic representation playing a postactivation verification role. According to Rayner et al. (1998) the false candidate of a homophone is more likely to slip by the verification procedure if it is orthographically similar to the correct mate or if the prior context strongly predicts the correct target word.

In contrast to the aforementioned studies that indicate that phonological codes are active very early in identifying a word, Daneman and Reingold (1993, Daneman, Reingold \& Davidson, 1995) conclued that phonological codes enter into the reading process at a later, postlexical, stage. In their experiments, participants read passages of text that contained homophones as their eye fixations were monitored. They found that fixation times on the correct homophone are shorter than those on the incorrect homophone and that fixation times on the incorrect homophone and spelling control are equal. These results would indicate that the appropriate meaning has been activated prior to the decision to move the eyes to the next word but that the phonological code has not yet been activated at this time. Moreover, Daneman et al. (1995) found that subjects detected the substitution of a homophone mate for a contextually appropriate homophone even when readers fail to make an overt error detection response. Consequently, according to Daneman et al., phonological involvement comes after orthographic analysis and is likely to be postlexical.

Given the strong evidence for early phonological coding found by Rayner et al. (1998), Inhoff \& Topolski (1994) and Jared, Levy \& Rayner (1999), some resolution of the difference between these studies and the finding of Daneman and Reingold (1993, Daneman et al. 1995) is needed. The present experiment was a further exploration of the Daneman et al. (1995) study : our participants read a text in which targets words were replaced by pseudohomophones and spelling controls pseudowords. If we found that pseudohomophones are mistaken for sound-alike words then this result implicates computed phonological codes as a source of error because pseudowords are not represented in the lexicon. Our experiment included two other stimulus manipulation : 1) the frequency of the word corresponding to the pseudoword, and 2) the orthographic similarity of the pseudoword to the appropriate word.

Our first manipulation was to vary the frequency of the word corresponding to the pseudohomophone and the spelling control. The verification hypothesis (Van Orden, 1987 ; Rayner et al., 1998) predicts that the likehood to make a mistake in response to pseudowords should be lowest when the corresponding word are high-frequency word. If the word corresponding to a pseudoword is a high-frequency word, readers are more likely to have complete knowledge of its spelling and are thus more likely to detect the pseudoword in the spelling check.

The second manipulation was to vary the orthographic similarity of the word-pseudoword pair. The motivation for this was that disambiguation of a false candidate through the verification process may be rapid and precise only if the false candidate and the correct word are orthographically dissimilar. Moreover, this effect of orthographic similarity must be more important for pseudohomophones because a false candidate is more likely to be available to the verification procedure if it is phonologically similar to a word (Van Orden, 1987 ; Van Orden et al., 1988 ; Rayner et al., 1998). 


\section{MATERIAL AND METHOD}

Twelve undergraduate students at the University of Villeneuve d'Ascq participated in the experiment. Each participant was individually tested in a session lasting approximately $45 \mathrm{~min}$.

In one text (French translation of Edgard Poe, "The Black Cat"), a set of 60 words (story-words) was choosen in such a way that they could be sorted into a high (30) and a low (30) frequency group. The mean frequency count was 33828 occurences per 100 millions for high frequency words and 1426 occurences for low frequency words (Content, Mousty \& Radeau, 1990). For each of the story-words, we constructed two yoked stimulus foils : a nonword homophone foil (pseudohomophone) and a nonword spelling control foil (control). For each of the frequency group, half (15) of the pseudohomophones and half (15) of the controls were orthographically similar to their corresponding target story-word. Degree of spelling similarity was calculated using an estimate of orthographic similarity (OS, Van Orden, 1987). Mean OS for the similarly spelled foils was 0.78 for pseudohomophones and controls. The other pseudohomophones (15) and their yoked controls (15) were orthographically less similar to their corresponding target story-word (mean OS was 0.42 for pseudohomophones and 0.41 for controls).

Four different error versions of this story were then constructed. In each version, one half of the correct story-words (30) were left in the story, and the other half were replaced by pseudohomophones (15) and controls (15). We accomplished counterbalancing of target stimulus across the four versions in such a way that no participant was presented with both the pseudohomophone and its corresponding control or with both a pseudoword and its correct story-word.

Participants were told that they would be presented a short story on successive screens of a computer monitor. They were instructed to read the story silently a their own pace and to press a button when they come across an error. The text was displayed on a 17" ViewSonic PT775 monitor in conventional upper- and lowercase. There were 37 screens of text, each containing no more than 9 double-spaced lines of text. When participants finished reading a screen they press a button to proceed to the next screen. Participants viewed the screen with their head positioned in a chin rest to minimize head movements. Viewing was binocular, but only the position of the right eye was measured and recorded.

Eye fixations were recording by a eye tracking system (ET4, AMtech GmBh) that calculated the x- and y- coordinates of the reader's point of regard every $5 \mathrm{~ms}$ with a resolution of $2 \mathrm{~min}$ of arc. Each button press was also stored with the eye tracking data. The eye tracker computer was interfaced with the display computer. The display was $45 \mathrm{~cm}$ from the participant's eye and two characters equaled $1^{\circ}$ of visual angle. A 5-point calibration was performed at the start of the experiment.

\section{RESULTS}

\section{False positive errors:}

A 2 (pseudoword type : pseudohomophone, control) x 2 (frequency of corresponding word : high, low) x 2 (orthographic similarity : high, low) analyse of variance (ANOVA) based on subject variability (F1) and item variability (F2) was carried out on this dependant variables.

For false positive errors, ANOVA yielded main effects of frequency, F1(1,11)=5.82, $\mathrm{p}=.03$ and $\mathrm{F} 2(1,112)=9.18, \mathrm{p}=.003$, and an interaction of pseudoword type and orthographic similarity, $\mathrm{F} 1(1,11)=6.26, \mathrm{p}=.02, \mathrm{~F} 2(1,112)=5.23, \mathrm{p})=.02$. The percentage of false positives to similarly spelled pseudohomophones $(31.94 \%$, table 1$)$ was significantly greater than that to less similarly spelled pseudohomophones $(14.58 \%), \mathrm{F} 1(1,11)=10.62, \mathrm{p}=.007, \mathrm{~F} 2(1,112)=6.89, \mathrm{p}=.009)$. This orthographic similarity effect was no significant for controls $(\mathrm{Fs}<1)$. In addition, in the similarly spelled condition, the error rate to pseudohomophones $(31.94 \%)$ was significantly greater than that for controls $(16.31 \%, F 1(1,11)=6.06, p=.03, F 2(1,112)=6.9, p<.01)$. Finally, with respect to the main frequency effect, post-hoc analysis indicated that significantly more errors were made on pseudohomophones based on low frequency story-words than on pseudohomophones based on high frequency story-words $(\mathrm{F} 1(1,11)=5.04, \mathrm{p}=.01, \mathrm{~F} 2(1,112)=11,05, \mathrm{p}<.001)$. This effect of frequency on pseudohomophones was not found on controls (Fs>.34). 
TABLE 1

Percentage of False Positive errors

\begin{tabular}{cccccccc}
\multicolumn{3}{c}{ Controls } & & \multicolumn{3}{c}{ Pseudohomophones } \\
& LF & HF & Mean & LF & HF & Mean \\
OS- & 21 & 15 & 18.40 & 27 & 2 & 14.58 \\
OS+ & 18 & 14 & 16.31 & 39 & 24 & 31.94 \\
Mean & 19.79 & 14.93 & & 33.33 & 13.19
\end{tabular}

Note. $\mathrm{HF}=$ High frequency $; \mathrm{LF}=$ Low frequency ;OS-=Less similarly spelled ; OS $+=$ similarly spelled.

Eye fixation data:

A 3 (stimulus type : pseudohomophone, control, correct word) x 2 (frequency : high, low) ANOVA was carried out on the first fixation duration. This ANOVA on the first fixation duration showed significant main effect of item type, $F 1(2,22)=5.14, p=0.01$ and $F 2(2,171)=6.66, p=0.001$. First fixation on pseudohomophones ( $236 \mathrm{~ms}$, see table 2) were equal to first fixation on correct words (216 ms, $F(1,11)=3.03, p>.1)$, but first fixation to controls (249 ms) were higher than on pseudohomophones $(\mathrm{F}(1,11)=13.8, \mathrm{p}<.004)$.

\section{TABLE 2}

First fixation duration (in milliseconds)

Correct word Pseudohomophone Control

$\begin{array}{rrrr}\text { HF } & 208 & 247 & 245 \\ \text { LF } & 224 & 224 & 253 \\ \text { Mean } & 216 & 236 & 249\end{array}$

Note. $\mathrm{HF}=$ High frequency $; \mathrm{LF}=\mathrm{Low}$ frequency.

A 2 (pseudoword type : pseudohomophone, control) x 2 (frequency of corresponding word : high, low) x 2 (orthographic similarity : high, low) ANOVA was carried out on total fixation time, which is the sum of all fixations on a stimulus including regressions, to correctly rejected pseudowords. This ANOVA on the total fixation showed significant main effects of pseudoword type, $\mathrm{F} 1(1,9)=9.95, \mathrm{p}=.01$ and $\mathrm{F} 2(1,109)=11.29, \mathrm{p}=.001)$ and frequency $\mathrm{F} 1(1,9)=11.51, \mathrm{p}=.007$, $\mathrm{F} 2(1,109)=.003$, see table 3 . Total fixation time on controls $(1325 \mathrm{~ms})$ was higher than on pseudohomophones $(981 \mathrm{~ms})$ and total fixation time on low frequency pseudowords $(1255 \mathrm{~ms})$ was higher than on high frequency pseudowords (1051 ms). 
In addition, analyses were carried out on pseudowords that were not detected by the readers (no button press). Readers took longer to process a control pseudoword (745 ms) than its contextually correct story-word $(388 \mathrm{~ms}), \mathrm{t} 1(10)=2.58, \mathrm{p}=.03$ and $\mathrm{t} 2(83)=3.41, \mathrm{p}<.001$. However, there was no difference in total fixation time for pseudohomophones (442 ms) versus correct words (388 ms), $\mathrm{t} 1(10)=1.94, \mathrm{p}>.08$ and $\mathrm{t} 2(83)=1.13, \mathrm{p}=.26$.

\section{TABLE 3}

Total fixation time (in milliseconds) to correctly rejected pseudowords

\begin{tabular}{ccccccc}
\multicolumn{3}{c}{ Controls } & & \multicolumn{5}{c}{ Pseudohomophones } \\
& LF & HF & Mean & LF & HF & Mean \\
OS- & 1336 & 1077 & 1206.9 & 903 & 727 & 815.6 \\
OS+ & 1600 & 1287 & 1443.9 & 1180 & 1112 & 1146.7 \\
Mean & 1468.4 & 1182.4 & & 1042.2 & 920.1 &
\end{tabular}

Note. $\mathrm{HF}=$ High frequency $; \mathrm{LF}=$ Low frequency ;OS-=Less similarly spelled ; OS+=similarly spelled.

\section{DISCUSSION AND CONCLUSION}

The proofreading data are consistent with a phonologic mediation model coupled with a verification hypothesis (Van Orden, 1987 ; Rayner et al., 1998). For Van Orden (1987), bottom-up activation comes from the phonological representation, whereas the verification process operate upon the orthographic representation. Then, a false candidate is more likely to be available to the verification procedure if it is phonologically similar to a correct word. In turn, a false candidate is more likely to slip by the verification procedure if it is orthographically similar to the stimulus word (thus the highest error rate to similarly spelled pseudohomophones foils). This verification hypothesis also correctly predicted the frequency effect observed in this study, that subjects made fewer errors to pseudohomophones foils that sounded like high frequency words.

The eye movements data are also consistent with this model. The first fixation duration to pseudohomophones and to correct words are statistically equal and less than those on the spelling control. This result is consistent with Inhoff and Topolski (1994) and suggests that phonological representations of the pseudohomophones activated the meaning corresponding to the correct target word. Moreover, these first fixation duration are comparable with those of Rayner et al. (1998), experiment 1 . They found $222 \mathrm{~ms}$ for first fixation to correct word and 245 to incorrect homophone word. This result is important because fixation times recorded in our study $(216 \mathrm{~ms}$ for correct word and $236 \mathrm{~ms}$ for incorrect homophone pseudoword) were not longer than fixation times recorded in other eye-tracking studies (see also Daneman et al. 1995), even when we required participants to make button-press responses to errors. Jared et al. (1999) suggest to interpreted with caution the Inhoff and Topolski (1994) experiment because eye fixation times reported in their study were considerably longer than in other eye-tracking studies, but this is not the case with our data. Concerning the first fixation duration, the phonological involvement has not been inferred from a slow secondary response. 
On correctly rejected pseudowords, the total fixation time are shorter for pseudohomophones than for spelling controls. This result indicates that phonology play a role in readers' reading of pseudoword. If we consider pseudowords that were not detected by the reader, then total fixation time on pseudohomophones and correct story-words were similar, whereas fixation time are longer for spelling controls than for correct story-words. As the fixation times on the correct word and incorrect homophones are statistically equal and less than those on the spelling control, then we can suggest that phonological codes have been activated by the time the decision is made to move the eyes to the next word but that orthographic coding has not progressed fully enough to distinguish between candidates in the verification process. This aspect of our data is in agreement with the data of Rayner et al. (1998) and would be consistent with a phonological coding model of lexical access which posits a primacy for phonological coding and that direct orthographic analysis is a second, spelling check stage of lexical access.

\section{REFERENCES}

Coltheart, V., Avons, S. E., \& Trollope, J. (1990). Articulatory supression and phonological codes in reading for meaning. Quarterly Journal of Experimental Psychology, 42A, 375-399.

Content, A., Mousty, P. And Radeau, M. (1990). Brulex : une base de données lexicales informatisée pour le français écrit et parlé. L'Année Psychologique, 90, 551-566.

Daneman, M., \& Reingold, E.M (1993). What eye fixations tell us about phonological recoding during reading. Canadian Journal of Experimental Psychology, 47, 153-178.

Daneman, M., Reingold, E.M. \& Davidson, M. (1995). Time course of phonological activation during reading : Evidence from eye fixation. Journal of Experimental Psychology : Learning, Memory, and Cognition, 21, 884-898.

Daneman, M., \& Stainton, M. (1991). Phonological recoding in silent reading. Journal of experimental psychology: Learning, Memory, and Cognition, 17, 618-632.

Inhoff, A.W. \& Topolski, R. (1994). Use of phonological codes during eye fixations in reading and in on-line and delayed naming task. Journal of Memory and Language, 36, 505-529.

Jared, D., Levy, B.A. and Rayner, K. (1999). The role of phonology in the activation of word meanings during reading : evidence from proofreading and eye movements. Journal of Experimental Psychology : Learning, Memory, and Cognition, 3, 219-264.

Rayner, K., Pollatsek, A. \& Binder, K.S. (1998). Phonological codes and eye movements in reading. Journal of Experimental Psychology : Learning, Memory, and Cognition, 24, 476497.

Rubenstein, H., Lewis, S. \& Rubenstein, M.A. (1971). Evidence for phonemic recording in visual word recognition. Journal of verbal learning \& Verbal behavior, 10, 645-657.

Van Orden, G.C. (1987). A rows is a rose : spelling, sound and reading. Memory and Cognition, 15, 181-198.

Van Orden, G.C., Johnston, J.C., \& Hale, B. L. (1988). Word identification in reading proceeds from spelling to sound to meaning. Journal of Experimental Psychology: Learning, Memory and Cognition, 14, 371-386. 


\section{APPENDIX}

Stimuli used in the experiment

less similarly spelled foils

Low frequency group

\begin{tabular}{|lll|}
\hline \multicolumn{1}{|c}{ Story-word } & \multicolumn{1}{c|}{ Pseudohomophones } & Controls \\
\cline { 2 - 2 } & amauniac & \\
bâtiment & batimand & Ameuniat \\
caresses & quaraices & Batimond \\
chaux & chot & Puaraices \\
crépi & krépi & Chol \\
embarras & ambarat & Orépy \\
enfer & anfaire & Imbaral \\
fantômes & phantaume & Onfoire \\
gibet & jibé & Plantaime \\
haleine & alaîne & Pibu \\
harmonie & armony & Alande \\
hideuse & ideuze & Armino \\
noeud & neux & Ideupe \\
quête & kaite & Nole \\
tonneaux & taunots & Foite \\
\hline
\end{tabular}

High frequency group

\begin{tabular}{|lll|}
\hline aspect & aspé & Aspi \\
assez & acé & Ari \\
autres & ôtres & Atlis \\
compte & konte & Ronte \\
corps & kaur & Kanr \\
enfance & anfense & Onfense \\
espèce & aispesse & Eispot \\
femme & phame & Plome \\
fort & phore & Plore \\
hasard & hazar & Haxar \\
morceaux & morçots & Morçats \\
objet & aubjet & Jobet \\
oiseaux & oizos & Oitous \\
péché & paichet & Prochat \\
tête & taite & Toite \\
\hline
\end{tabular}




\begin{tabular}{|lll|}
\multicolumn{3}{c}{ Similarly spelled foils } \\
\hline \multicolumn{2}{|c|}{ Low frequency group } \\
Story-word & Pseudohomophones & \multicolumn{1}{c|}{ Controls } \\
alcool & alcôl & Alcil \\
atmosphère & atmosfère & Atmoslère \\
chimères & schimères & Choimaines \\
croyance & croillance & Croithance \\
docilité & daucilité & Dancilité \\
excès & eccès & Encès \\
faubourgs & fauxbourgs & Fautbourgs \\
gravats & gravâts & Gravûs \\
morne & maurne & Mourne \\
pression & préçion & Prédion \\
remords & remaurs & Renourds \\
singe & sinje & Sinpe \\
sorcières & sorciaires & Sorgières \\
soupçons & soupsons & Souprons \\
supplice & suplisse & Supliffe \\
\hline & &
\end{tabular}

High frequency group

\begin{tabular}{|lll|}
\hline action & axion & Alcion \\
camarade & kamarade & Tamarade \\
caractère & quaractère & Puaractère \\
chaise & chèze & Dhaise \\
chambre & chembre & Chamble \\
chemin & chemain & Chemoin \\
conscience & consience & Canscience \\
direction & diréxion & Diropion \\
étrange & étranje & Etrampe \\
honte & onte & Hoinne \\
maison & maizon & Mailon \\
position & posission & Posippion \\
raison & rêson & Rôson \\
réflexion & réflexion & Réflendion \\
rêves & raives & Roives \\
\hline
\end{tabular}

